\title{
Baleia, de Graciliano Ramos: Uma Meditação Sobre a Vida Sensível do Animal
}

FERNANDA COUTINHO

Universidade Federal do Ceará

\begin{abstract}
In this essay, I examine the status of Baleia, the family dog in Graciliano Ramos's Vidas secas (1938). My principal interest is to analyse the attenuation of distances and the differentiation of sensibility between humans and animals in the novel. I argue that Baleia allows Ramos to leave aside an absolute belief in human reasoning and think of the nonhuman animal as a being endowed with complexity. In this, Ramos deviates from a speciesist appreciation of history and sharpens the gaze of his readers with respect to the limitations of our understanding of the world and its beings.
\end{abstract}

Keywords: Human; sensibility; speciesism; Vidas secas; Brazilian novel

A história das relações entre animais e seres humanos é uma das mais antigas e, assim, ambos vêm sendo colocados lado a lado, desde tempos que remontam aos primórdios da história da arte. A literatura brasileira é rica neste particular, oferecendo uma expressiva gama de figurações, destacando-se em sua produção animalista a presença do cachorro. ${ }^{1}$ Entre as personagens caninas da ficção brasileira, Baleia, a famosa cadelinha, personagem de Vidas secas (1938), criação de Graciliano Ramos é, sem dúvida, uma das mais conhecidas e vem

\footnotetext{
${ }^{1}$ Além de alentada produção esparsa, a ficção animalista brasileira deu oportunidade, por exemplo, ao surgimento, em 1947, da antologia Dez Histórias de bichos, organizada por João Condé. Dez escritores entraram nessa "arca improvisada," como a denominou o poeta Carlos Drummond de Andrade, que para ela escreveu uma espécie de prefácio. Contos brasileiros de bichos traz textos de Monteiro Lobato a Nélida Piñon. Mais recentemente foi publicada A linguagem dos animais com contribuições, para a zooliteratura brasileira, de Machado de Assis e Carlos Drummond de Andrade, entre outros.
} 
suscitando numerosas interpretações no âmbito dos estudos literários, desde a publicação da obra.

O presente trabalho pretende discutir o estatuto ficcional de Baleia, efetuando-se a análise da categoria personagem, por intermédio da atenuação de distâncias/diferenciações de sensibilidade entre homem e animal. O ponto de partida para o texto é a premissa de que, em sua composição, o escritor alagoano deixa de lado a crença absoluta na razão humana, pretensamente capaz de tudo desvendar, e pensa o animal não humano como dotado de complexidade, no que se afasta de uma apreciação especista da história, aguçando o olhar dos leitores em potencial para as limitações que cercam nosso entendimento do mundo e dos seres.

Em entrevista a João Condé, Graciliano revela ter a cachorra Baleia começado a nascer, muito antes de ele mesmo se dar conta, uma vez que foi concebida a partir de uma lembrança visual de sua infância - um cachorro sacrificado, em Maniçoba, no interior de Pernambuco. A história de Baleia foi publicada primeiramente como conto, em função da necessidade de sobrevivência do escritor, recém-saído da prisão que lhe fora imposta pelo Estado Novo getulista. À época, Graciliano escreveu as treze narrativas de Vidas secas, de forma isolada, sendo o capítulo sobre Baleia, o nono do livro, o primeiro a ser finalizado. Compôs assim o que Rubem Braga, seu companheiro de pensão no Catete, à época, chamou de "romance desmontável." De acordo com Dênis de Moraes, antes de 1938, a narrativa apareceu, em periódicos brasileiros, com títulos diversos, além de ter sido publicada no jornal La Prensa, de Buenos Aires, por intermédio de Benjamín de Garay, amigo de Graciliano e seu futuro tradutor (Moraes 161-62).

Na realidade, foi Heloísa Ramos, esposa do escritor, quem em primeiro lugar ouviu falar do animal, "que era como uma pessoa da família, sabida como gente" (Ramos, Vidas 34). Em carta a ela dirigida, datada de 7 de maio de 1937, Graciliano confessa seu desconforto na sondagem desse "outro," que em seu enigma, põe à prova o entendimento humano: "Escrevi um conto sobre a morte duma cachorra, um troço difícil, como você vê: procurei adivinhar o que se passa na alma duma cachorra. Será que há mesmo alma em cachorro? Não me importo. O meu bicho morre desejando acordar num mundo cheio de preás" (Ramos, Cartas 276). Essa é uma passagem que ilustra o passo de Graciliano, em direção contrária ao especismo, na medida em que, movido pela radicalidade, anula a 
distância entre homens e animais, ambos agora situados na esfera da expectação, como se lê no trecho seguinte da mesma carta: "Exatamente o que todos nós desejamos. No fundo somos todos como a minha cachorra Baleia e esperamos preás" (Ramos, Cartas 276). É intrigante que seja exatamente uma metáfora animal o traço de união entre pessoas e bichos. E nas duas situações, o preá desponta como elemento vital; concretamente, como roedor, para a sustentação da vida; e, de forma abstrata, como símbolo da necessidade de consolo do homem, em sua pequenez e desamparo diante do mundo, malgrado sua proverbial autossuficiência.

Como tal, o ficcionista fornece dados para a verificação do modo como a literatura vem tratando o convívio entre o homem e os animais não humanos. Essa tem sido uma temática particular da zooliteratura, aqui definida, lato sensu, por Maria Esther Maciel, pesquisadora que está entre as primeiras estudiosas do tema na América Latina: "Uso a palavra 'zooliteratura' para designar o conjunto de diferentes práticas literárias ou de obras (de um autor, de um país, de uma época) que se voltam para os animais" (14).

Os estudos animais, plataforma multidisciplinar composta pela literatura e por outras formas de conhecimento como o filosófico, o das ciências humanas e biológicas e ainda do direito, e que são sustentados por dois eixos, "o que concerne ao animal propriamente dito e à chamada 'animalidade,' e o que se volta para as complexas e controversas relações entre homens e animais nãohumanos," têm retomado o especismo como debate da contemporaneidade (Maciel 5). Essa forma de avaliação do mundo vem atravessando, no correr dos séculos, o pensamento de filósofos, tal como Michel de Montaigne, que se posicionou contrariamente à colocação do ser humano como centro do universo, fazendo, ao invés disso, o elogio do animal. Sua definição do homem comporta extremos, pois o avalia como "a mais frágil e miserável" de todas as criaturas, e paradoxalmente, ao mesmo tempo "a mais orgulhosa" (184). Para Montaigne, a presunção humana é responsável pela segregação do "outro," já que o sujeita a uma hierarquia artificial. Assim é que, na "Apologia de Raymond Sebond," afirma:

Pela vaidade mesma dessa imaginação, iguala-se a Deus, atribuindo-se a si próprio qualidades divinas, que ele mesmo escolhe. Separa-se das outras criaturas; distribui as qualidades 
físicas e intelectuais que bem entende aos animais, seus companheiros. Como pode conhecer com sua inteligência os móveis interiores e secretos deles? Em virtude de que comparações entre eles e nós chega à conclusão de que são estúpidos? (184)

O exercício da dúvida une, portanto, as duas sensibilidades, criando um diálogo imaginário entre o filósofo e o ficcionista, ambos relativizando a clivagem entre as diferentes formas de animalidade.

No caso de Graciliano, Baleia vai representar a situação de mais intenso aprofundamento sobre a relação homem-animal, inclusive pelo fato de colocar em xeque um atributo que, principalmente pelo entendimento da religião, é considerado apanágio dos humanos: a consciência da morte. $\mathrm{O}$ cristianismo, de modo particular, aceita o fato de o animal partilhar com o homem a condição da mortalidade, embora ele não saiba que irá morrer. Ao teatralizar a morte de Baleia, aproximando o universo dos bichos do registro existencial, o romancista faz vacilar diante dos olhos do leitor esse predicado que é entendido como um traço de singularidade do ser humano. ${ }^{2}$

Não apenas Baleia compõe o zoo de Graciliano, outros animais a ele se integram, tal como o cachorro Tubarão, que em S. Bernardo guarda a entrada da fazenda de igual nome, um dos cenários de seu segundo romance. Tubarão, contudo, não é individualizado por seu criador, aparecendo apenas como associado à ideia de fidelidade, predicado tomado como característica da espécie canina. Nesse sentido, na história de Paulo Honório, Graciliano cria uma imbricação de personalidades entre Tubarão e o sertanejo Casimiro Lopes, cão de guarda do protagonista: "Veio sentar-se num degrau da calçada. Picando fumo com a faca de ponta e preparando o cigarro de palha, deitava os olhos de cão ao prado, ao açude;" "Calado, fiel, pau para toda obra" (144). Em outro trecho de S. Bernardo, o sertanejo chega a ser inteiramente identificado com o cachorro: "Na casa-grande, que Tubarão e Casimiro Lopes guardavam, a vida era uma tristeza, um aborrecimento" (158).

\footnotetext{
${ }^{2}$ Em Perto do coração selvagem, Clarice Lispector destaca essa ignorância através de uma percepção da meditativa e questionadora criança, Joana: "Encostando a testa na vidraça brilhante e fria olhava para o quintal do vizinho, para o grande mundo das galinhas-que-não-sabiam-queiam-morrer" (13).
} 
No universo animalista de Graciliano, a experiência mais próxima da radicalidade expressa em Baleia, somente vai reaparecer em "Minsk," conto de Insônia, que ficcionaliza a qualidade fraterna e essencial da relação da criança com um periquito, cuja descrição corresponde a uma explosão de vida: "Não era um cara-suja ordinário, de uma cor só pequenino e mudo. Era um periquito grande, com manchas amarelas, andava torto, inchado e fazia: —Eh! Eh!” (61). Uma atitude eufórica é verificável em Luciana, a menina da história, ao receber a ave de presente: "abriu muito os olhos espantados, [...] deu um grito selvagem, mistura de admiração e triunfo" (Ramos, Insônia 61). Essa expressão de encantamento equivale ao primeiro sinal do nó afetivo que se estabelece entre ela e Minsk, o periquito. A narração avizinha o animal e a criança, por efeito da descrição psicológica de ambos os seres: "Minsk era também um ser disposto às aventuras e à liberdade" (64). Os dois actantes, além disso, são caracterizados por um determinante comum: o adjetivo selvagem. Ao expor essa superposição, o contista opta por associar a personagem humana à noção de animalidade, tornando a experiência entre a criança e a ave muito mais visceral, porque não tem a racionalidade como parâmetro definidor. O processo de descoberta do mundo para Luciana é inteiramente mediado pelo modo de ser da ave e essa situação atinge seu paroxismo, quando a morte do periquito leva a menina a penetrar no abismal mistério da finitude.

Não se pode esquecer ainda da presença do papagaio em Vidas secas, o que dá a conta inicial de seis viventes para o grupo em marcha. Logo no primeiro capítulo, todavia, é sacrificado por sinha Vitória, que alega ser ele "mudo e inútil" (12). Não há personagens loquazes neste relato e o próprio narrador justifica o mutismo da ave imitadora. "Não podia deixar de ser mudo. Ordinariamente a família falava pouco. E depois daquele desastre viviam todos calados, raramente soltavam palavras curtas" (12). Mesmo sendo tão fugidia a participação do papagaio na narrativa, o fato de o louro apenas aboiar "tangendo um gado inexistente," e latir "arremedando a cachorra" projeta a aridez verbal da família de Fabiano, sua debilidade como seres de linguagem (12). Em capítulo posterior, a memória de sinha Vitória lamenta a morte do bicho, recuperando-lhe a voz minguada: "Pobre do papagaio. Viajara com ela, na gaiola que balançava em cima do baú de folha. Gaguejava: "Meu louro." Era o que sabia dizer. Fora isso aboiava arremedando Fabiano e latia como Baleia. Coitado" (43). 
Em função da publicação inicial de sua história no formato de conto, Baleia foi desvelada, de princípio, no drama de sua morte. Quanto ao escritor, a primeira reação foi revelar-se temeroso quanto à acolhida da narrativa, em meio a seus pares, como relata Moraes, um de seus biógrafos:

Os habituês da livraria José Olympio estranhariam o sumiço de Graciliano. Pode parecer irreal, mas o fato é que, por uns dois ou três dias, o nosso romancista não colocaria os pés fora da pensão. Tinha-se convencido de que dera um escorregão com o conto da cachorra. Bobagem. Na tarde em que tomou coragem para enfrentar os monstros sagrados da roda literária, Afonso Arinos, Augusto Frederico Schmidt e José Lins do Rego o aguardavam com palavras de admiração. José Maria Belo o chamaria a um canto:

Graça, você acredita que eu chorei com o sacrifício de Baleia?

—Será que estava tão piegas assim? —responderia Graciliano, quase numa recaída. (161-62)

Esse pequeno fait divers da história literária brasileira assinala a atitude de severa autocrítica adotada pelo escritor, em todo o período de sua interação com a linguagem, a qual incluía a ética do narrar, o que o impediria de resvalar para o lacrimoso, e bem poderia ser sintetizada por meio de uma frase-súmula de sua poética: "A palavra não foi feita para enfeitar, brilhar como ouro falso; a palavra foi feita para dizer" 3 (Ramos, citado em Silveira, 284).

Reportando-se a Vidas secas, em Ficção e Confissão, Antônio Candido observa ser o relato "constituído por cenas e episódios mais ou menos isolados, alguns dos quais foram efetivamente publicados como contos; mas são na maior parte, por tal forma solidários, que só no contexto adquirem sentido pleno" (45). Naturalmente, a apreciação extensiva da obra fornece maior embasamento acerca da viagem dos retirantes e da cachorra, contudo, mesmo a leitura isolada do capítulo sobre a morte do animal encena um percurso no tempo, por intermédio

\footnotetext{
${ }^{3}$ Veiculada inicialmente pela entrevista concedida a Joel Silveira em 1938, a afirmação seria transcrita mais tarde em Silveira 284. Ver ainda: Ramos, Conversas 77.
} 
dos diversos flashes de memória que faíscam na mente da protagonista. São esses lampejos de lembranças que reforçarão o registro existencial há pouco aludido. Nesse sentido, vale sublinhar que em "Os bichos do subterrâneo," ao referir-se a Vidas secas, assinalando o abandono dos relatos em primeira pessoa dos romances anteriores de Graciliano, Cândido pondera ainda que o escritor "conserva, sob a objetividade da terceira pessoa, o filete da escavação interior," escavação que inclui Baleia, porque intuída como um ser portador de dramaticidade (87).

A personagem Baleia proporciona uma leitura de rara plasticidade, em todo o livro e particularmente no capítulo que lhe é especialmente dedicado. A plasticidade se inaugura pela descrição marcadamente naturalista: "A cachorra Baleia estava para morrer. Tinha emagrecido, o pêlo caíra-lhe em vários pontos, as costelas avultavam num fundo róseo, onde manchas escuras supuravam e sangravam, cobertas de moscas. As chagas da boca e a inchação dos beiços dificultavam-lhe a comida e a bebida (Ramos, Vidas secas 85)." Vidas secas vem inaugurar uma nova fala dentro do romance nordestino de 30, pelo fato de atenuar o componente mesológico adotado por A Bagaceira, de José Américo de Almeida, e $O$ Quinze, de Rachel de Queiroz, por exemplo, em favor de um realismo subjetivista, transcrito na "fuga persistente ao documental, bem expressa na sobriedade das descrições de paisagem, na ausência de tons coletivistas e na concentração de atenções sobre a família de Fabiano" (Cristovão 38). Como tal, após a crueza do retrato, que encima a história, surpreende a forma como o escritor constrói uma narração em câmera lenta, com o ritmo cortante das enumerações em série do parágrafo introdutório, dando lugar a uma desaceleração dos eventos, no compasso gerundial do verbo finar-se.

O compasso moroso deverá ter surpreendido ainda bem mais a quem leu o texto como uma narração autônoma, sem dispor dos dados da "biografia" da cadelinha, esparsos nos oito capítulos anteriores do livro. Pode-se dizer que Graciliano constrói uma biografia de Baleia ao longo do texto, porque os pequenos acontecimentos dessas vidas parcas têm, como filtro, em muitas ocasiões, a sensibilidade da cadela. $O$ escritor molda-a como um ser de percepção e desta forma questiona a apreensão do mundo apenas por meio de uma lógica racional ou da sensibilidade do animal humano. Em outras palavras, é como se Graciliano quisesse dizer que a história das pessoas também é contada pelos 
bichos, no caso de Baleia, especificamente por meio de suas "pupilas brilhantes" (11), orelhas arrebitadas, ventas arregaçadas, seu "ouvido atento" (14).

Contudo, mesmo o leitor do texto autônomo vai poder, em certa medida, reconstituir a vida de Baleia, pois esse é um capítulo-puzzle, em que pela memória do sentimento, a personagem contracena com a família de retirantes, em êxodo pelo sertão: o vaqueiro Fabiano, sinha Vitória, sua mulher, e os dois filhos pequenos do casal. O exílio, como experiência de inospitalidade, é vivido por esse grupo que percorre a caatinga maltratada pela seca, encontrando, finalmente, uma fazenda abandonada, onde se instala, até que, mais uma vez, acossado pela estiagem, prossegue em seu périplo, rumo talvez a um caminhar contínuo em que o horizonte deixa entrever uma existência digna, unicamente como miragem. Baleia não irá até o fim da jornada, porque Fabiano sacrifica-a por conta da suspeita de hidrofobia. Será sua morte, porém, um sinal definitivo de desaparecimento? Terá ela morrido, de fato, para ele? A resposta muito provavelmente é não, pois o Fabiano de poucas palavras adensa sua vida sensível, encarreirando muitos remordimentos após esse gesto. Dos quatro capítulos finais, ela apenas não reaparecerá trazida por seu pensamento em "O soldado amarelo." De "Contas," pode-se depreender a capacidade da literatura para marcar o convívio entre pessoas e animais, visto que neste livro em que a noção de família é muito cerrada, o animal é naturalizado como criatura plena, pela locução "como se," no interior de uma comparação pungente. Após a injustiça e humilhação sofridas junto ao patrão, o sertanejo procura se recompor emocionalmente trazendo para junto de si aquilo que lhe parece ser o aconchego: "Deixara a rua. Levantou a cabeça, viu uma estrela, depois muitas estrelas. As figuras dos inimigos esmoreceram. Pensou na mulher, nos filhos, na cachorra morta. Pobre da Baleia. Era como se tivesse matado uma pessoa da família" (Ramos, Vidas secas 99 ).

Em "O mundo coberto de penas," além de reprisar a imagem de um Fabiano introspectivo ("suspirou, sentiu um peso enorme por dentro. Coitadinha da cadela. Matara-a forçado pela moléstia" (115)), Graciliano, em mais um paralelo animal, amplia um sintagma definidor do estado de ânimo do vaqueiro, em algumas passagens da narração. Em vez do "coração grosso," lê-se agora "coração grosso, como um cururu", para enfatizar a dolorida lembrança de Baleia: "Coitadinha, magra, dura, inteiriçada, os olhos arrancados pelos urubus" (Ramos, Vidas secas 115). O tônus hiperbólico avança pelo último capítulo 
("uma grande saudade espremeu-lhe o coração" (121)), o que, por um lado, denota um espessamento psicológico da personagem do matuto, e, por outro, revela a capacidade de o homem se importar com esse outro, tão próximo, quanto o bicho.

Embora a baleia seja um animal mamífero, pelo fato de viver na água, a tradição popular associa-a aos peixes e assim a cachorra da família deveria favorecer-se da virtude mágica que preconiza que "o poder do nome é tanto que, para os cachorros se livrarem da hidrofobia, basta dar-lhes o nome de peixes como cação, cirigado, tubarão, toninha, piranha" (Cascudo 423). Sua morte negaria o sortilégio, embora não fique de todo patente na narrativa ter sido a raiva a causa do acontecido, a ponto de ressoar uma dúvida na mente de sinha Vitória: "achava difícil Baleia endoidecer e lamentava que o marido não houvesse esperado mais um dia para ver se realmente a execução era indispensável" (Ramos, Vidas secas 87).

Em outro trecho da carta, remetida à esposa, em 7 de maio de 1937, com o livro em processo de composição, como é sabido, Graciliano fornece dele uma pista de leitura, através de uma radiografia sumária de seus personagens: "É a quarta história feita aqui na pensão. Nenhuma delas tem movimento, há indivíduos parados. Tento saber o que eles têm por dentro" (Ramos, Cartas 27677). O próprio escritor oferece subsídios sobre o subjetivismo da construção da narrativa, e, na formulação da dúvida, explicita seu intuito com a escrita da composição. Que criaturas vão transparecer desse olhar que se embrenha no mundo adverso, para daí capturá-los? Sem dúvida, criaturas sub-humanas, seres rudes e quase primitivos, reféns da "hostilidade do mundo físico e da injustiça humana," nas palavras de Ramos (Conversas 68). ${ }^{4}$

A constatação dessas qualidades decorre em grande medida da parcimônia de vocabulário desses personagens de vidas minguadas, parcimônia que provocou o seguinte comentário de Rolando Morel Pinto: "Como pouco se fala, a relação dos gestos enumerados, segundo uma ordem lógica, lembra a representação do cinema mudo. A falta de diálogos tem de ser compensada pela configuração exterior dos personagens, das suas ações, dos movimentos que suprirão as comunicações verbais" (Pinto 47). Embora o autor, nesta obra, não se utilize de um narrador em primeira pessoa, o desafio de saber o que os

\footnotetext{
${ }^{4}$ A explicação apareceu originalmente em Broca.
} 
personagens "têm por dentro" (Ramos, Cartas, 194) faz com que ele adote como estratégia narrativa o emprego do discurso indireto livre, acompanhando, em boa parte, o relato em terceira pessoa. A fortuna crítica do escritor muito tem falado sobre seu domínio dessa técnica de escrita, para realizar essa introspecção na "alma" do personagem, agudizada na circunstância da morte.

"Baleia" não é um capítulo longo, ocupa até menos espaço no livro do que "Festa" ou "Fuga," cujos títulos revelam uma acentuada predisposição à narratividade moldada em acontecimentos. Embora não seja longo, aparenta ser até mais extenso do que os outros, pois sua leitura se dá num compasso de lentidão, motivado por muitas paradas, tal como pensado por Roland Barthes em "Escrever a leitura," seção de O Rumor da língua. No ensaio, Barthes propõe uma dupla pergunta, e mostra as pausas da leitura como motor do pensamento: "Nunca lhe aconteceu, ao ler um livro, interromper com frequência a leitura, não por desinteresse, mas, ao contrário, por afluxo de ideias, excitações, associações? Numa palavra, nunca lhe aconteceu ler levantando a cabeça?" (26).

A concepção da morte de Baleia, como um drama íntimo, ocasião em que contracena, por intermédio do afeto, com todos os personagens da família, encerra anacronias, que extremam na analepse correspondente à recordação de seu nascimento. "Não poderia morder Fabiano: tinha nascido perto dele, numa camarinha, sob a cama de varas, e consumira a existência em submissão, ladrando para juntar o gado quando o vaqueiro batia palmas" (Ramos, Vidas secas 89). Seria possível, assim, imaginar um insulamento significativo entre homem e animal não humano, quando o escritor os une através de uma meditação sobre a própria morte feita pelo personagem canino? O liame entre os dois reflete-se também por meio da semântica do sofrimento: o "coração pesado" de Baleia encontra sua correspondência no "coração grosso" de Fabiano, já referido. E, num reforço ao movimento de aproximação entre bicho e homem, o padecimento da cachorrinha encontra a seguinte formulação: "Uma angústia apertou-lhe o pequeno coração" (Ramos, Vidas secas 90).

Logo, com base no exercício de escrita do ficcionista nordestino, é possível afirmar que o que faz a literatura, em sua condição de experiência de descentramento do real, nesse caso, é conduzir o leitor a uma re-interpretação do mundo circundante, a qual pode levá-lo a pensar sobre a incompreensível vaidade humana de que falava Montaigne. Como compreendê-la, quando a finitude é o único horizonte possível para todas as criaturas? Com a construção dessa anti- 
fábula, que se preocupa com a natureza da convivialidade entre homens e animais e ainda com a expressão da singularidade do animal não humano, Graciliano proporciona ao leitor um exercício de encontro com a outridade, como apontado por Otto Maria Carpeaux:

Certamente a alma deste romancista seco não é seca; é cheia de misericórdia e de simpatia para com todas as criaturas, é muito mais vasta do que um mestre-escola filantrópico pode imaginar; abrange até o mudo assassino Casimiro Lopes, até a cachorrinha Baleia, cuja morte me comoveu imensamente: 'Tat twan asi.' $(30)^{5}$

Nas palavras de Vinciane Despret:

Pela sua proximidade connosco, pela sua capacidade de sentir o amor, de reconhecer a lealdade, de agir com generosidade, de admirar ou de antecipar, o cão como o macaco é mobilisado por [Charles] Darwin no seu projeto de remissão em causa do excepcionalismo humano. (161)

A partir dessa afirmação, vê-se que igualmente que a ciência, aí representada por Darwin, junta-se ao parecer de Montaigne e Graciliano, questionando a soberania do homem, junto aos outros animais, e, simultaneamente, manifestando a potência de vida sensível dos bichos, particularmente o macaco e o cachorro. Por esse ângulo, ao longo desse trabalho, foi visto que Baleia bouleversa esse romance áspero, que é Vidas secas, canalizando o olhar do leitor para o abrandamento da rígida segregação, que foi instituída entre homens e animais. Prova disso é a dialética criada por Graciliano, nesse romance, no que tange ao

\footnotetext{
${ }^{5}$ Casimiro Lopes, pertence a $S$. Bernardo, e é outra personagem que foge à univocidade, pois deixa à mostra o caráter, no mínimo, dual de sua psicologia. Sua ferocidade de assassino implacável não o impede de compadecer-se do desprezo a que é relegada a criança mofina que é o filho de Paulo Honório e Madalena: "Casimiro Lopes era a única pessoa que lhe tinha amizade. Levava-o para o alpendre e lá se punha a papaguear com ele, dizendo histórias de onças, cantando para embalá-lo as cantigas do sertão" (161). Tat twam asi tem como tradução: "você é isso!" Era a expressão utilizada na antiga Índia, para definir a sensação experimentada por um homem, ao voltar sua percepção sensorial para o mundo.
} 
aprender/ensinar, a qual faz com que o animal promova a sondagem interior dos personagens, principalmente a do chefe da família, o que cria uma hesitação sobre o estatuto de personagens do grupo de Fabiano, habitualmente tomadas como pessoas toscas e embrutecidas pelo sofrimento. O escritor nos leva a intuir: Por que não pensar que as explicações para o mundo podem surgir de outros horizontes que não a racionalidade?

Não sem razão, portanto, Baleia é, no século vinte, a personagem canina mais célebre de nossa literatura, devendo-se grifar que existem outras grandes criações nesse âmbito, sendo possível lembrar, igualmente, a rosiana Pingo-de-ouro, uma "cachorra bondosa e pertencida de ninguém, mas que gostava mais era dele mesmo [...] no sentir de Miguilim" (Rosa 20), e ainda Vismundo, o cão de prima Biela, de Uma vida em segredo, novela escrita por Autran Dourado. Essas criaturas animais sucedem à geração nascida no século dezanove, e expandem um veio literário, fundado por meio de, entre outros, o famoso Veludo, protagonista do longo poema "História de um cão," de Luís Guimarães Júnior, publicado em 1870. ${ }^{6}$ Trata-se do mesmo ano do aparecimento dos Contos fluminenses, de Machado de Assis, sendo "Miss Dollar," o primeiro deles. A cadelinha galga, dona de uma coleira fechada ao pescoço por um cadeado, em que se lia a terna inscrição De tout mon coeur, expressa a afeição como um modelo de relacionamento entre as pessoas e os cães. No caso de Quincas Borba, o romancista embaralha os estatutos humano e animal, pela indiferenciação da nomeação do filósofo e de seu cachorro, aspecto que torna a personagem cara aos Estudos Animais, o que pode ser evidenciado em "Machado pós-humanista" (Maciel 74-82).

Com Vidas secas, Graciliano incorporou definitivamente seu nome à escrita animalista brasileira, e colaborou para firmar a identidade e a afinidade de nossa literatura com essa vertente, inclusive pelo fato de fazer oscilar categorias tidas como estanques, tais como zoomorfização e antropomorfização. Somente por isso, já ficaria sem sentido a definição dada por ele mesmo, em discurso, à sua produção literária— “arte capenga adquirida em Palmeira dos Índios” (Moraes

\footnotetext{
${ }^{6}$ Logo após o título, lê-se a informação: “Contada ao autor.” É esse o modo pelo qual Luís Guimarães Júnior credita sua inspiração a "Moustapha-Histoire d'un chien," conto de Adolphe Destroyes. O poema de Guimarães contem também referências a naturalistas franceses do século XIX: "Toussenel, Figuier e a lista imensa/ Dos modernos zoólogos doutores/ Dizem que o cão é um animal que pensa:/ Talvez tenham razão esses senhores" (108).
} 
196) — na ocasião em que parte expressiva da intelectualidade brasileira se reunia, no restaurante Lido, no Rio de Janeiro, em 1942, para comemorar seus 50 anos de vida. Como poderia ele se sentir um deslocado no mundo da escrita se em sua palavra se encontra o mais profundo sentido de humanidade? E se o que buscava era "demonstrar empatia e solidariedade a todos os infelizes que povoam a terra" (Moraes 196)?

\section{Obras citadas}

Almeida, José Américo de. A Bagaceira. José Olympico, 1928.

Andrade, Carlos Drummond de. "A Rosa do povo." Reunião: 10 livros de poesia. José Olympio, 1974, pp. 105-06.

Despret, Vinciane. "L'animal est une personne: Entretien avec Vinciane Despret." Chiens, chats... Pourquoi tant d'amour? Belin, 2015, pp. 123-80.

Barthes, Roland. "Escrever a leitura." O rumor da língua, tradução de Mário Laranjeira, Martins Fontes, 2004, pp. 26-29.

Broca, Brito. "Vidas secas: Uma palestra com Graciliano Ramos-O sertanejo da zona árida - O homem no seu habitat.” A Gazeta, 15 Mar. 1938, p. 8.

Candido, Antonio. Fiç̧ão e confissão: ensaios sobre Graciliano Ramos. Ed. 34, 1992.

Carpeaux, Otto Maria. "Visão de Graciliano Ramos." Graciliano Ramos, editado por Sônia Brayner, Civilização Brasileira, 1978, pp. 25-33.

Cascudo, Luís da Câmara. Dicionário do folclore brasileiro. Global, 2002.

Condé, João, editor. 10 histórias de bichos. Condé, 1947.

Cristovão, Fernando Alves. Graciliano Ramos: estrutura e valores de um modo de narrar. Cosmos, 1998.

Destroyes, Adolphe. "Moustapha-Histoire d'un chien." Chefs-d'œuvre des prosateurs français au XIXe siècle, edição de Victor Tissot e Louis Charles Collas, Delagrave, 1882, pp. 289-99.

Dourado, Autran. Uma vida em segredo. Civilização Brasileira, 1964.

Guimarães Júnior, Luís. Sonetos e rimas. Academia Brasileira de Letras, 2010.

Lispector, Clarice. Perto do coração selvagem. Rocco, 1998.

Maciel, Maria Esther. Literatura e animalidade. Civilização Brasileira, 2016.

Montaigne, Michel de. "Apologia de Raymond Sebond." Ensaios, livro II, tradução de Sérgio Milliet, U de Brasília/Hucitec, 1987, pp. 173-307. 
Moraes, Dênis de. O velho Graça: uma biografia de Graciliano Ramos. José Olympio, 1996.

Pinto, Rolando Morel. Estudos de romance. Conselho Estadual de Cultura, 1965. Queiroz, Rachel de. O Quinze. José Olympio, 1930.

Ramos, Graciliano. Cartas. Record, 2011.

- Conversas, edição de Ieda Lebensztayn e Thiago Mio Salla, Record, 2014, pp. 66-72.

-. Insônia. Record, 2003.

-. S. Bernardo. Record, 2008.

—. Vidas secas. Record, 2003.

Rosa, João Guimarães. Corpo de baile. Nova Fronteira, 2010.

Silveira, Joel. Na fogueira: memórias. Mauad, 1998. 